\title{
A Causal Model of Voluntary Turnover Among Nursing Personnel in Long-Term Psychiatric Settings
}

\author{
Jeffrey A. Alexander, ${ }^{1,2 *}$ Richard Lichtenstein, ${ }^{1,2} \uparrow$ \\ Hyun Joo Oh, ${ }^{2+}$ Esther Ullman $^{2 *}$
}

\author{
${ }^{1}$ University of Michigan, School of Public Health, Department of Health Management and Policy, \\ 109 Observatory, Ann Arbor, MI 48109 \\ ${ }^{2}$ Serious Mental Illness Treatment Research and Evaluation Center (SMITREC), \\ Ann Arbor, VA HSR\&D \\ Received 24 February 1997; accepted 10 April 1998
}

\begin{abstract}
Causal modeling was used to explore the processes by which individual characteristics, job satisfaction, and intention to quit explain turnover among nursing personnel in 29 Department of Veterans Affairs (VA) long-term psychiatric settings. The sample consisted of 1,106 registered nurses (RNs), licensed practical nurses (LPNs), and nurses' aides. We conceptualized turnover as a multistage process linking social and experiential orientations, attitudes toward the job, the decision to quit, and the behavior of actually quitting. Intention to quit was the strongest direct predictor of turnover. Professional growth opportunities and workload were important indirect predictors of turnover. Dissatisfaction with work hazards and relationships with coworkers were both indirect and direct predictors of turnover. Attitudes towards the job varied by nursing group. LPNs and aides were less satisfied than RNs with autonomy and work hazards. RNs were more dissatisfied with workload. We conclude that strategies to promote retention need to address aspects of jobs tailored to specific nursing groups. () 1998 John Wiley \& Sons, Inc. Res Nurs Health 21: 415-427, 1998
\end{abstract}

Keywords: nursing turnover; job satisfaction; intention to quit; long-term psychiatric care; causal modeling

As the dominant treatment modality for serious long-term mental illnesses has shifted from maintenance and custodial care to active treatment and psychosocial rehabilitation, greater emphasis has been placed on continuity of care and active therapeutic relationships between provider and patient (Anthony, 1990; Cnaan, Blankertz, Messinger, \& Gardner, 1988; Minkoff, 1987). To provide such care, psychiatric treatment organizations must be concerned with recruiting highly motivated caregivers, providing them with the appropriate training, and ensuring that they view their contribu- tions to patient care as important and their jobs as satisfying (Anthony, Cohen, Farkas, \& Cohen, 1988). Historically, however, nursing personnel in long-term psychiatric facilities have displayed higher levels of stress, lower job satisfaction, and a higher propensity to quit than providers working in other types of health care settings (Cameron, Horsburgh, \& Armstrong-Stassen, 1994; Depp, Arnold, Dawkins, \& Selzer, 1983). Despite the voluminous body of research on nursing turnover, in only a small proportion of this work have the causes of turnover among nursing personnel in psychi-

Funding for this research was provided by the Mental Health Strategic Health Group of the Veterans Health Administration Headquarters.

Correspondence to Jeffrey Alexander.

*Professor.

${ }^{\dagger}$ Research Scientist.

${ }^{\ddagger}$ Associate Professor. 
atric treatment settings been examined (Parkes \& Rabenau, 1993). The little work that has been conducted in these settings has been largely exploratory, with samples of fewer than 50 nursing staff.

The aim of this study was to develop and test a causal model of turnover among nursing personnel (registered nurses [RNs], licensed practical nurses [LPNs], and nurses' aides) working in psychiatric units that predominantly treat patients with long-term serious mental illnesses. More specifically, the purposes of the study were (a) to identify those aspects of the work of psychiatric nursing personnel that predicted most their intention to leave their jobs and actual turnover and (b) to identify the elements of work and the workplace that were salient to different groups of psychiatric nursing personnel.

The study was intended to advance our understanding of turnover among nursing staff in several important ways. First, by focusing exclusively on nursing personnel working in psychiatric settings. This approach was designed to avoid inappropriately generalizing findings from studies conducted in nonpsychiatric institutions to psychiatric settings. Second, our sample of psychiatric nursing personnel was considerably larger and more diverse than those employed in previous studies, which strengthens both the internal and external validity of the findings. Finally, we developed and tested a theoretical model that incorporates elements of both needs-satisfaction and social information processing determinants of job satisfaction among nursing personnel and their subsequent effects on intent to leave and turnover. This model represents an advance over previous research in that it specifies processes by which turnover occurred among different types of nursing staff in a particular work setting. Such an approach provides a stronger basis for designing targeted interventions to increase job satisfaction and reduce turnover among psychiatric nursing personnel.

Our theoretical model of turnover (Figure 1) among nursing personnel in psychiatric treatment settings conceptualized turnover as a multistage attitudinal, decisional, and behavioral process (Irvine \& Evans, 1995). The behavioral component of the model focused on the act of separating from a job. This behavior is predicted by the decisional component of the model, usually intent to leave, which directly affects behavior and, at the same time, represents the intervening variable between turnover and other antecedents of turnover (Mobley, Horner, \& Hollingsworth, 1978; Para- suraman, 1989; Price \& Mueller, 1981; Weisman, Alexander, \& Chase, 1980). Although our proposed model conforms generally to this established approach, it places particular emphasis on the relative importance of specific dimensions of job satisfaction that influence intention to quit and on personal attributes of nursing personnel that may shape such attitudes toward their job.

Our theory represents a middle ground between two opposing perspectives on the relationship between job attitudes and behavior (Schneider, 1987; Stamps \& Piedmonte, 1986; Staw \& Ross, 1985; Weiss \& Adler, 1984). The first, often termed the needs-satisfaction perspective, posits that individuals have unique, enduring needs and that jobs have specific, objective characteristics. The conjunction or fit of these two elements results in job attitudes that, in turn, influence turnover intentions and behavior. The opposing theory, termed the social information processing perspective, holds that individual predispositions (including needs and expectations) are situationally determined and that attitudes are socially constructed as a function of social contexts and consequences of past behavior and choices (Davis-Blake \& Pfeffer, 1989; Salancik \& Pfeffer, 1978).

Our theoretical framework combines elements of both these perspectives and is based on the assumption that individual attributes that reflect social and experiential orientations will interact with situational factors to shape work attitudes and behaviors. The theory goes beyond the common notion that nursing staffs' job satisfaction will independently influence their intentions to remain in their position. Rather, it suggests that nursing staffs' attitudes toward their work and the workplace will, in part, be shaped by their training, experience, and referent group (social network). Attitudes toward the job are not exogenous nor are they universal to all nursing personnel. They are, rather, an interactive product of what the nursing staff bring to the work situation and the work situation itself. Such interactions will result in varying levels of satisfaction with particular aspects of the job for particular categories of nurses. Metaanalyses of turnover studies provide strong support for this perspective. Cotton and Tuttle (1986), for example, found that correlates of turnover varied with the employee group under study. Turnover was found to be less reliably tied to pay for nonmanagerial employees and more strongly tied to pay for professional workers.

A key implication of the theory is that different categories of nursing personnel are likely to be 


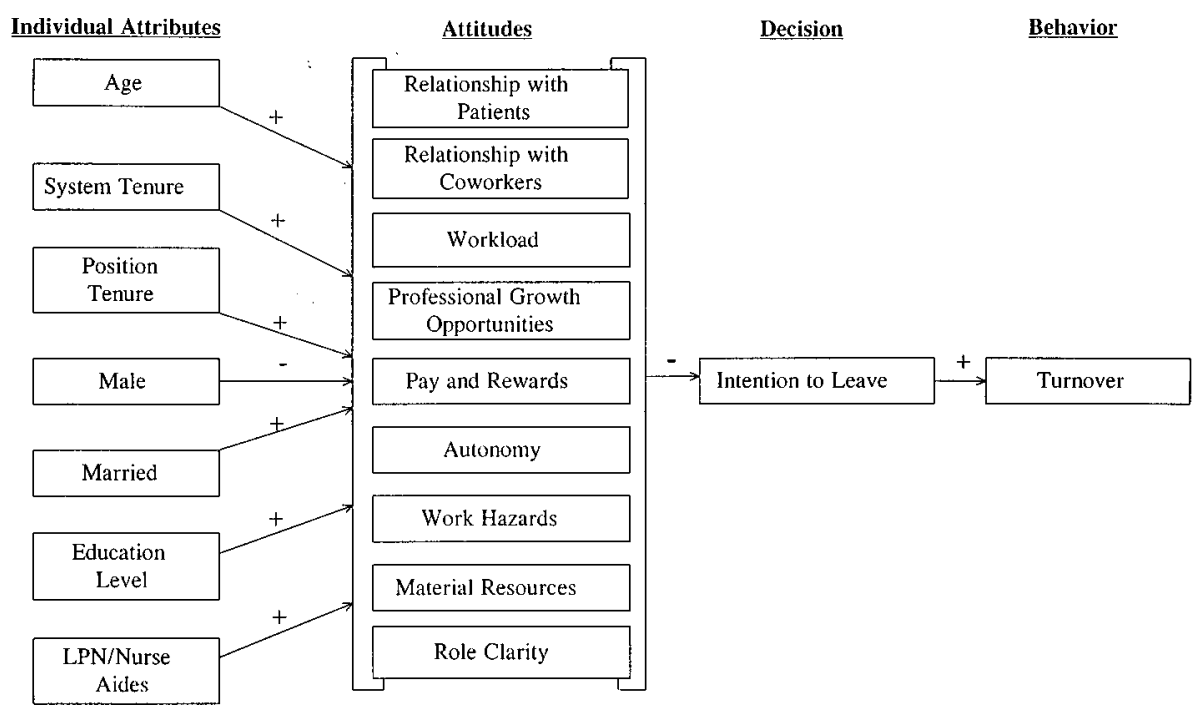

FIGURE 1. Theoretical model of turnover and intention to quit among psychiatric nursing personnel (LPN $=$ licensed practical nurse).

more or less affected by different aspects of the job and the workplace. For example, older nursing staff may be less dissatisfied with promotional opportunities compared with younger staff, but more concerned with the physical demands of their work. To the extent that these issues relate to intention to quit and actual quitting behavior, there may exist different pathways to turnover for specific categories of nursing personnel.

As reflected in Figure 1, our model incorporates causal linkages between key individual attributes (e.g., age and occupation) and attitudes toward the workplace that potentially influence turnover (e.g., satisfaction with workload, pay, and rewards). Specifically we examined six attributes of nursing personnel that reflect their social and experiential orientation and are posited to differentially affect job satisfaction: age, gender, tenure, marital status, level of education, and type of nursing training. Previous investigators have linked age and tenure to both job satisfaction and turnover, with older workers and those with longer tenure more likely to be satisfied with and less likely to leave their jobs (Benedict, Glasser, \& Lee, 1989; Coward et al., 1995; Price \& Mueller, 1981). In addition, investigators have shown women and married workers have higher levels of job satisfaction than their male and unmarried counterparts (Coward et al., 1995; Dunkin, Stratton, Harris, Juhl, \& Geller, 1994; Hinshaw \& Atwood, 1983). Finally, level of education and RN training have been positively related to job satis- faction (Hinshaw \& Atwood, 1983; Huey \& Hartley, 1988; Price \& Mueller, 1981).

We also examined nine dimensions of job satisfaction that may affect nursing personnel's intention to leave and turnover. The dimensions have been examined in previous research (see Table 1) and are relevant to nursing personnel in units that care for patients with serious long-term mental illnesses. These include satisfaction with: (a) relationships with patients - the degree to which working with patients represents a source of stimulation and enjoyment; (b) relationships with coworkers - the degree to which a member and her fellow workers share trust and confidence in one another; (c) workload - the degree to which the amount of work required interferes with the ability to meet patient needs and deliver high quality care; (d) professional growth opportunitiesthe degree of potential upward occupational mobility in the organization; (e) pay and rewards - the degree to which monetary and nonmonetary compensation is consistent with responsibility, ability, and workload; (f) level of autonomy - the degree of discretion an individual is able to exercise in the performance of her job; (g) work hazards - the degree to which the job entails physical exertion, stress, and risk; (h) availability of material resources - the degree to which appropriate program funding and physical resources are available; and (i) role clarity - the degree to which information about the tasks and responsibilities associated with the job is conveyed by the organi- 
Table 1. Means and Standard Deviations of Personal Characteristics of Nursing Personnel by Occupational Category

\begin{tabular}{lcccc}
\hline & \multicolumn{4}{c}{ Occupational Category } \\
\cline { 2 - 5 } Personal Characteristics & RN & LPN & Aides & Total \\
& 444 & 152 & 510 & 1106 \\
\hline Age (years) & 46.01 & 43.19 & 43.59 & 44.53 \\
& $(9.34)$ & $(10.49)$ & $(10.13)$ & $(9.93)$ \\
Gender (\% women) & 0.85 & 0.85 & 0.54 & 0.71 \\
& $(0.36)$ & $(0.36)$ & $(0.50)$ & $(0.45)$ \\
Marital Status (\% married) & 0.33 & 0.44 & 0.45 & 0.40 \\
& $(0.47)$ & $(0.50)$ & $(0.50)$ & $(0.49)$ \\
Education (years) & 15.13 & 13.49 & 12.40 & 13.66 \\
& $(1.36)$ & $(1.29)$ & $(1.70)$ & $(1.97)$ \\
Tenure in the VAMC (years) & 11.20 & 9.25 & 12.12 & 11.34 \\
& $(7.72)$ & $(6.92)$ & $(8.54)$ & $(8.05)$ \\
Tenure in Current Position (years) & 5.59 & 6.65 & 10.25 & 7.82 \\
& $(6.23)$ & $(5.98)$ & $(8.65)$ & $(7.69)$ \\
\hline
\end{tabular}

Note. $\mathrm{LPN}=$ licensed practical nurse; $\mathrm{RN}=$ registered nurse; VAMC $=$ Veterans Affairs Medical Center.

zation to its members. Although all nine dimensions are posited to relate negatively to intent to leave, the strength of these relationships is assumed to vary as a function of their importance to particular categories of nursing personnel.

From our theoretical framework, we derive the following hypotheses:

$\mathrm{H}_{1}$ : Among the nine dimension-specific measures of job satisfaction, the level of job satisfaction of psychiatric nursing personnel will vary by personal attributes corresponding to experience, social network, and training. Specifically, higher job satisfaction on each dimension will be expressed by nursing personnel who have $\mathrm{RN}$ training (relative to LPNs and aides), are older, female, more educated, have longer tenure, and are married.

$\mathrm{H}_{2}$ : Intent to leave among psychiatric nursing personnel is negatively, but differentially, associated with multiple dimensions of job satisfaction.

$\mathrm{H}_{3}$ : Voluntary turnover among psychiatric nursing personnel is positively associated with intent to leave.

\section{METHOD}

\section{Sample}

This analysis was part of a larger study by the U.S. Department of Veterans' Affairs (VA) Serious Mental Illness Treatment Research and Evaluation Center (SMITREC) . The goal of the study was to improve the quality of psychosocial and medical care in the VA's 29 long-term neuropsychiatric hospitals. These hospitals are distributed throughout the United States and their primary mission is to provide long-term psychiatric care to veterans with mental illnesses. As part of the evaluation of the SMITREC, we conducted a longitudinal assessment of staff in 102 units in the 29 VA hospitals. All outpatient units and 2 inpatient units were selected at each hospital from all long-term units meeting eligibility requirements. Units were eligible if $50 \%$ or more of their patients met two conditions: (a) diagnosis of a psychosis (e.g., schizophrenia, major mood disorder, and dementia) and (b) documented cumulative length of stay in a psychiatric unit in one or more Veterans Affairs Medical Centers (VAMCs) of at least 150 days in the past year, or five or more admissions to psychiatric units of one or more VAMCs in the past year. In this paper we present data on 94 units, 54 inpatient units and 40 outpatient units, which represented all units that had nursing staff assigned to them. Ninety-three percent of these nursing staff worked on inpatient units. We focus only on RNs, LPNs, and aides who staffed during the day or afternoon shifts. Descriptive data on the personal characteristics of the sample members are presented in Table 1.

\section{Data and Measures}

The source of data on turnover was the unit staffing report. This report was submitted to research staff every 6 months by coordinators in all 
Table 2. Job Satisfaction Scale Items, Sources, and Alphas

\begin{tabular}{|c|c|c|c|c|}
\hline $\begin{array}{l}\text { Dimensions of } \\
\text { job satisfaction }\end{array}$ & $\begin{array}{l}\text { Number } \\
\text { of items }\end{array}$ & Sample item & Alpha & $\begin{array}{l}\text { Previous use in job } \\
\text { satisfaction studies }\end{array}$ \\
\hline $\begin{array}{l}\text { Relationships with } \\
\text { patients }\end{array}$ & 7 & $\begin{array}{l}\text { I enjoy working with the kinds } \\
\text { of patients I work with. }\end{array}$ & .89 & $\begin{array}{l}\text { Hackman, 1987; Davis-Sacks, } \\
\text { 1991; Lichtenstein, 1984; Caudill } \\
\text { \& Patrick, 1989; Greishaber et al., } \\
1995\end{array}$ \\
\hline $\begin{array}{l}\text { Relationships with } \\
\text { coworkers }\end{array}$ & 5 & $\begin{array}{l}\text { I have a strong feeling of trust } \\
\text { in the people I work with. }\end{array}$ & .84 & $\begin{array}{l}\text { Stamps \& Piedmonte, 1986; Price } \\
\quad \& \text { Meuller, } 1981\end{array}$ \\
\hline Workload & 4 & $\begin{array}{l}\text { I have too much work to do } \\
\text { everything well. }\end{array}$ & .78 & $\begin{array}{l}\text { Stamps \& Piedmonte, 1986; Price } \\
\quad \& \text { Meuller, } 1981\end{array}$ \\
\hline Professional growth & 4 & $\begin{array}{l}\text { There are good opportunities } \\
\text { here for professional growth } \\
\text { and development. }\end{array}$ & .79 & $\begin{array}{l}\text { Stamps \& Piedmonte, 1986; Price } \\
\quad \& \text { Meuller, } 1981\end{array}$ \\
\hline Pay and rewards & 5 & $\begin{array}{l}\text { I am rewarded fairly considering } \\
\text { the responsibilities I have. }\end{array}$ & .76 & $\begin{array}{l}\text { Price \& Meuller, 1981; Stamps \& } \\
\text { Piedmonte, 1986; Hackman, } \\
1987\end{array}$ \\
\hline Autonomy & 4 & $\begin{array}{l}\text { This job denies me any chance } \\
\text { to use personal initiative or } \\
\text { judgment in carrying out the } \\
\text { work. }\end{array}$ & .72 & $\begin{array}{l}\text { Stamps \& Piedmonte, 1986; } \\
\text { Hinshaw \& Atwood, 1983; } \\
\text { Weisman et al., 1980; } \\
\text { Lichtenstein, } 1984\end{array}$ \\
\hline Work hazards & 3 & $\begin{array}{l}\text { The physical work involved in } \\
\text { my job (e.g., lifting patients) } \\
\text { exposes me to potential injury. }\end{array}$ & .71 & $\begin{array}{l}\text { Blegen \& Mueller, 1987; Packard \& } \\
\text { Motowidlo, 1987; Price \& Mueller, } \\
\text { 1981; Hackman, 1987: task and } \\
\text { environment }\end{array}$ \\
\hline Material resources & 3 & $\begin{array}{l}\text { This hospital has all the equip- } \\
\text { ment I need to do my job well. }\end{array}$ & .60 & $\begin{array}{l}\text { Price \& Meuller, 1981; Lichtenstein, } \\
\quad 1984\end{array}$ \\
\hline Role clarity & 3 & $\begin{array}{l}\text { On my job, tasks and responsi- } \\
\text { bilities are clearly defined. }\end{array}$ & .66 & $\begin{array}{l}\text { Price \& Meuller, 1981; Davis-Sacks, } \\
\text { 1991; Zautra et al., } 1986\end{array}$ \\
\hline Intention to quit & 3 & $\begin{array}{l}\text { There is a good chance that I } \\
\text { will leave this job in the next } \\
\text { year or so. }\end{array}$ & .83 & $\begin{array}{l}\text { Price \& Meuller, 1981; Mobley et al., } \\
\text { 1978; Weisman et al., } 1980\end{array}$ \\
\hline
\end{tabular}

94 sample programs and contained both a complete listing of staff assigned to the program and a reconciliation with the previous staffing report. In addition to the names of the staff members, the report provided information on the date of assignment to the unit, date of exit (if applicable), reason for exit, percent time assigned to the unit, and occupation.

Our primary dependent variable, voluntary turnover, indicated whether an RN, LPN, or aide voluntarily exited the unit or program to which he or she was assigned during the 18-month period following the administration of the job-satisfaction survey. Voluntary turnover includes cases in which the individual left the VA system, transferred to another VA facility, or transferred to another program within the same facility. It does not include exits for reasons such as involuntary terminations (infrequent), retirement, illness or death, nor did it include temporary transfers of 6 months or less.
Intention to quit and the nine dimensions of job satisfaction were measured, via a survey of staff satisfaction, as mean scores on multi-item indices. The items were patterned after instruments used in previous job-satisfaction research in health care settings, but modified as appropriate to mental health delivery. For example, based on site visits and discussion with clinical care staff, items on work hazards and relationships with patients were added, changed, or both, to reflect work with the seriously mentally ill (see Table 2 for sample questions and sources of satisfaction scales). These items were pretested with mental health staff at a VA acute care hospital, modified as necessary, piloted at 4 VA psychiatric hospitals, and then sent to the remaining 25 facilities.

Each job-satisfaction item was scaled on a 7point agree-disagree continuum. All negatively worded items were reverse coded so that a higher mean score on an index always reflects a higher level of satisfaction on that dimension. Confirma- 
tory factor analysis indicated that the scales had acceptable discriminant validity (results available from authors). The number of items contained in each index, along with the scales' alpha coefficients, are shown in Table 2.

Six demographic and background variables related to the individual attributes of nursing personnel were employed in the analysis. Education was an interval variable corresponding to the highest grade of school or year of college/graduate school completed. Marital status was coded as $0=$ single, widowed, or divorced and $1=$ married. Age was the respondent's age in years. Gender was coded as $0=$ male and $1=$ female. Two versions of tenure were used. System tenure was measured as the number of years worked in the VA health care system. Position tenure was measured as the number of years in the current position in the unit. Occupation was coded as a dichotomous variable, where $0=R N$ and $1=L P N$ or aide. Although we recognize that the educational backgrounds and training of LPNs and aides differ, we combined these two occupational groups because the work they do is similar. Our primary interest was in differentiating the work orientation and attitudes of RNs, who tend to hold leadership positions, from those of other nursing staff, who often are more directly involved in the care of patients.

\section{Procedures}

The data collection period, September to December 1992, preceded a major reorganization of the VA, which included downsizing of programs. Data collection procedures were as follows: site coordinators at each facility provided a listing of all clinical staff assigned to the sample units. We deleted any staff who worked the night shift or who were not involved in direct patient care. Questionnaires were mailed to the site coordinator with a video tape that described the importance of the study and explained how our survey procedures would protect respondent confidentiality. Site coordinators set up group meetings with relevant staff in the units during normal working hours. Following a screening of the video, the questionnaires were distributed. Staff returned the questionnaires to the coordinators in a sealed envelope that had a control number on the front but no name identification. Staff had the option of returning the survey blank or marking it "refused" if they did not wish to complete it. Research staff sent letters directly to individuals who initially refused to complete the questionnaires asking them to reconsider that decision. To ensure confidentiality, the site coordinators were not informed whether or not a potential respondent completed the questionnaire.

This process resulted in a return rate of $97 \%$, of which $94 \%$ were sufficiently complete for analyses. We attribute the high response rate to a combination of factors including carefully planned survey administration, strong support of the study by VA Medical Program and VA labor union leadership, and the intrinsic interest the study seemed to hold for the staff. Demographic characteristics of staff, contained on the listings supplied to us by site coordinators, enabled us to compare survey respondents and nonrespondents. No nonresponse bias was observed for any occupational or demographic group.

\section{Analysis}

Structural equation modeling permitted the simultaneous identification of direct and indirect paths leading to turnover. To estimate the path coefficients we used LISREL 8 with the asymptotic covariance matrix as the input matrix. This covariance matrix was estimated using weighted least squares (WLS) estimation procedures because the ordinal variables were not assumed to be multivariate normal (Joreskog and Sorbom, 1993) and because our sample size was large enough to handle this estimation procedure.

Although we approached the specification of our structural model on the basis of theoretical relationships discussed previously, identification of the final model involved dropping nonsignificant paths, as well as adding paths indicated by the modification indices. The final, trimmed model, which was reached after nine iterations, thus represents the interplay of our theoretical arguments about turnover and the model that best fits our data. It includes only those paths that together best explain the process of turnover among nursing personnel in long-term psychiatric settings. Estimates of the path coefficients allowed tests of our proposed hypotheses (Asher, 1983; Klem, 1995).

Because LISREL can produce more than one model that fits the data, we employed three different statistics to identify the best fitting, final model. First, we used the chi-square test to assess the goodness of fit between the reproduced and observed covariance correlation matrices. To ensure that the final model fit the data better than other potential combinations, we also applied two additional tests of fit: the goodness of fit Indices (GFI/Adjusted GFI) and the Root Mean Square Error of Approximation (RMSEA) residual (Asher, 1983; Klem, 1995). GFI values of .90 or higher indicate an adequate fit; a RMSEA value of .05 
or smaller indicates a close fit with the data $(\mathrm{Cu}-$ deck \& Browne, 1983).

\section{RESULTS}

Descriptive statistics and zero-order correlations among the variables in our study are reported in Tables 3 and 4. Over one third of the nursing personnel in our sample $(35 \%)$ voluntarily left their position, the VA system, or both, during this 18month period. Average scores on the dimensions of job satisfaction ranged widely. Nursing personnel were least satisfied with work hazards and were most satisfied with role clarity and their relationships with coworkers.

The final structural model and the standardized path coefficients are displayed in Figure 2. The chi-square goodness of fit for the model was not significant, $\chi^{2}(21, n=1106)=23.26, p=0.33$, suggesting that the model fit the data well. The other statistics also supported this conclusion (GFI goodness of fit index $=1.00$; AGFI adjusted goodness of fit index $=0.99$; RMSEA $=0.0099$ ).

The configuration of the final model conformed generally to our theoretical predictions. That is, turnover among nursing personnel in long-term mental health units was a direct function of inten-

Table 3. Means and Standard Deviations of Variables in the Turnover Model

\begin{tabular}{lrr}
\hline Variable & $M$ & $S D$ \\
\hline Turnover & 0.35 & 0.48 \\
Intent to quit & 3.10 & 1.59 \\
Workload & 3.70 & 1.34 \\
Autonomy & 4.27 & 1.30 \\
Work hazards & 2.90 & 1.35 \\
Relationship with & 5.00 & 1.24 \\
$\quad$ co-workers & & \\
Professional growth & 3.78 & 1.50 \\
$\quad$ opportunities & & \\
Role clarity & 5.10 & 1.07 \\
Relationships with patients & 4.99 & 0.99 \\
Pay and rewards & 3.73 & 1.23 \\
Material resources & 3.69 & 1.35 \\
LPN/Nurse aides & 0.60 & 0.49 \\
Education & 13.66 & 1.97 \\
Age & 44.53 & 9.93 \\
Gender & 0.71 & 0.45 \\
Tenure in the VAMC & 11.34 & 8.05 \\
Tenure in current position & 7.82 & 7.69 \\
Marital status & 0.40 & 0.49 \\
\hline
\end{tabular}

Note. $\mathrm{LPN}=$ licensed practical nurse; VAMC $=$ Veterans Affairs Medical Center. tion to quit. Intention to quit, in turn, was predicted by level of satisfaction with specific dimensions of work. As anticipated, the higher the level of satisfaction on these dimensions, the less likely nursing personnel were to intend to quit and therefore to actually exit their unit or program. It is important to note, however, that the effects of many of the job-satisfaction dimensions on turnover and intention to quit varied both in terms of effect size and order. Finally, nursing personnel with particular background characteristics were more likely predisposed to hold certain attitudes toward their jobs. Specifically, LPNs and nurses' aides were less satisfied than RNs with autonomy and work hazards. RNs were less satisfied than LPNs and aides with their workload. By contrast, nursing personnel with higher levels of education (controlling for type of nurse training) were more disposed to exhibited higher levels of satisfaction with their workload and lower levels of satisfaction with job hazards than nursing personnel with less education.

Although the final structural model revealed some exceptions to these general patterns (discussed below), the sequence of variables and the strength and direction of the path coefficients clearly supported these proposed relationships and, in general, were consistent with our theoretical framework (Goodell-Tarnowski \& Van Ess Coeling, 1994; Lucas, Atwood, \& Hagaman, 1993).

Most dimensions of satisfaction affected turnover through their effects on intention to quit. Specifically, satisfaction with professional growth opportunities, autonomy, workload, and role clarity were significant predictors of intention to quit, which in turn, was a significant predictor of turnover. Among these job-satisfaction dimensions, opportunities for professional growth, relationship with coworkers, autonomy, and workload were the strongest predictors of intention to quit. In further support of our model, satisfaction with coworker relations and job hazards also exercised a direct effect on turnover. The higher the satisfaction level on these dimensions, the less likely nursing personnel were to intend to quit and to actually exit their unit.

Several background and demographic attributes of nursing personnel affected intention to quit and turnover directly rather than indirectly operating through job satisfaction. Gender, for example, affected turnover through intention to quit. Female nursing personnel were less likely to intend to quit than their male counterparts. Age, on the other hand, had a direct and negative path to turnover indicating that older nursing personnel 


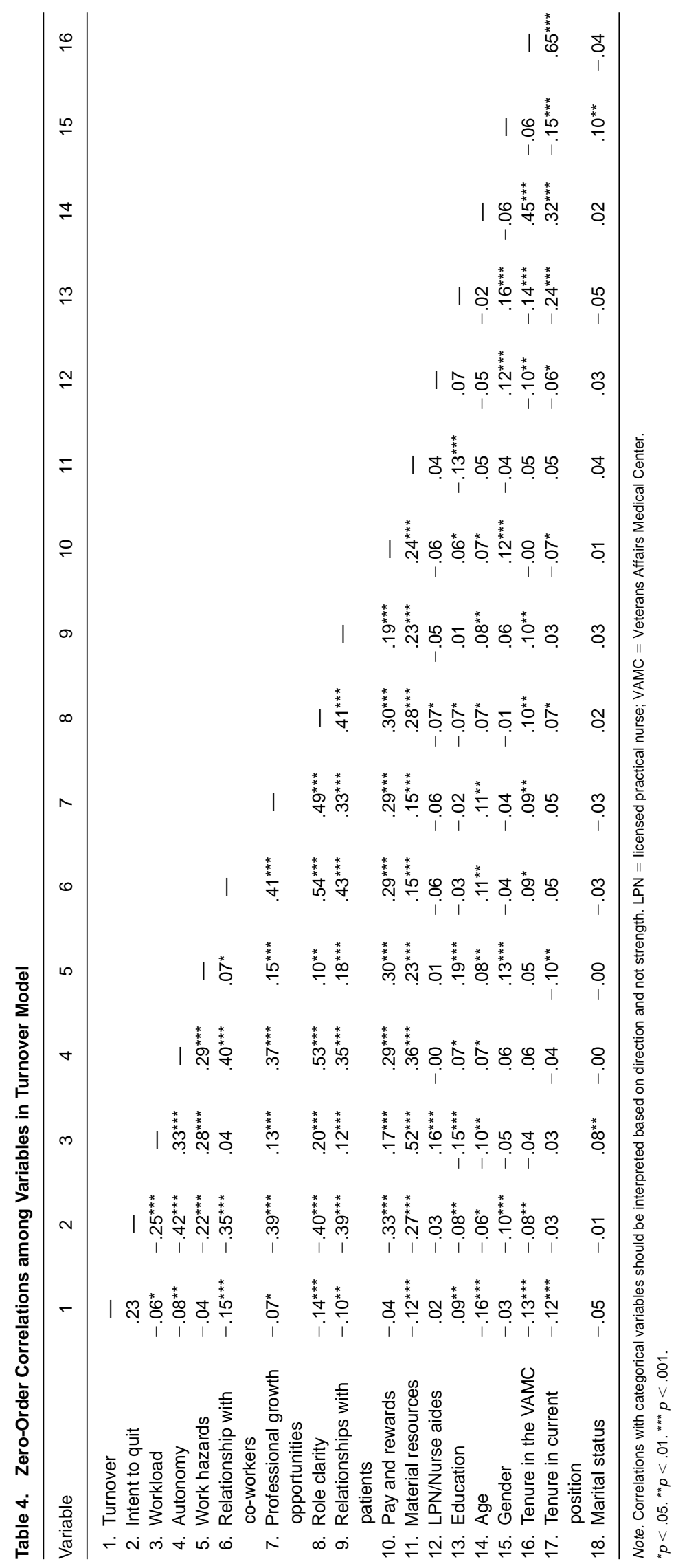




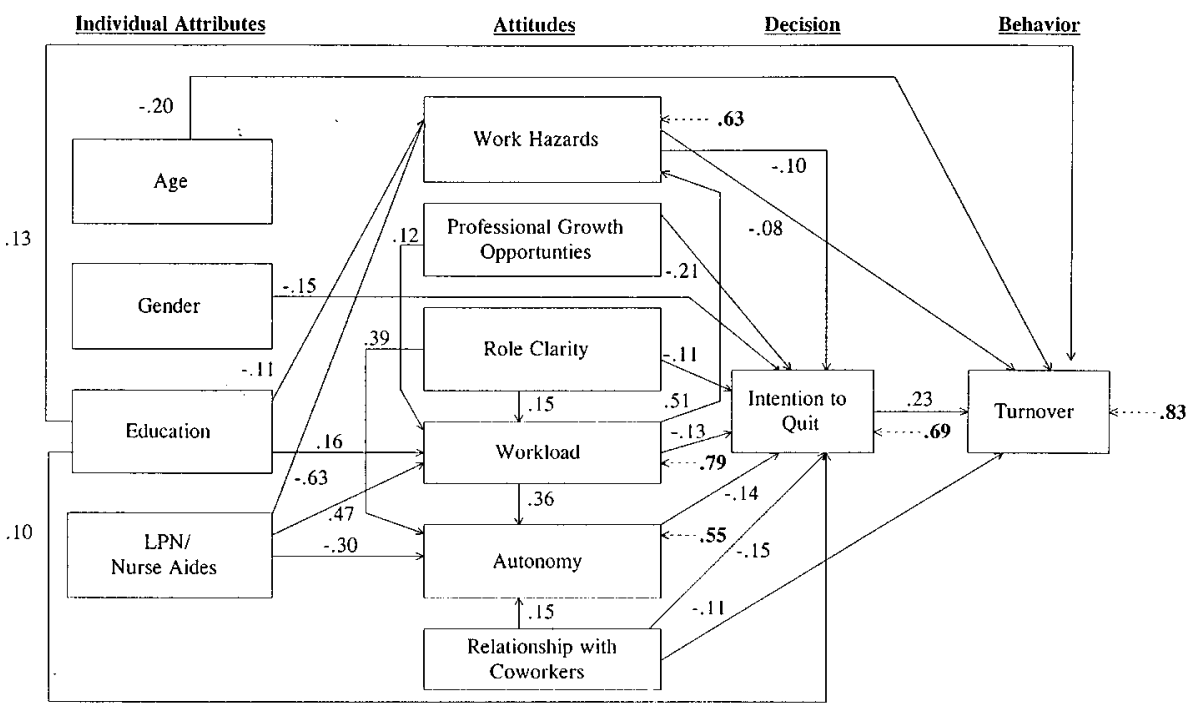

FIGURE 2. Final path model of intention to quit and turnover (standardized coefficients shown). Dashed lines with bold numbers indicate error variances. (LPN = licensed practical nurse).

were less likely to voluntarily exit their units or programs than younger nursing personnel.

Several job satisfaction and individual nurse attributes are not featured in the final LISREL model, suggesting that their impact on intention to quit and turnover is negligible when other variables in the model are controlled and the final model is fitted. These attributes included both forms of tenure (VA and position), marital status, satisfaction with pay and benefits, satisfaction with material resources, and satisfaction with relationship with patients.

Figure 2 also displays the error variances for each multiple regression performed on the endogenous variables. Of the total variation in intention to quit, $31 \%$ was explained by satisfaction with workload, autonomy, job hazards, relations with coworkers, professional growth opportunities, role clarity, level of education, and gender. Intention to quit, level of education, age, and satisfaction with job hazards and coworker relations explained $17 \%$ of the variance in turnover. The remaining endogenous variables in the model, satisfaction with workload, autonomy, and job hazards, had 21,45 , and $37 \%$ of their respective variances explained by their direct predictors.

\section{DISCUSSION}

Based on our path model, intention to quit was the most important predictor of actually leaving the job. This finding demonstrates that for many nursing personnel in long-term psychiatric facilities turnover is a process rather than a single, discrete event. That is, before actually leaving the job, nursing staff typically have made a conscious decision to do so and these two events are usually separated in time. Although this finding supports our model about the nature of turnover, our path model also lends insight into the underlying factors that increase intention to leave.

For example, job satisfaction plays an integral role in our model, representing a key component in the decision-making process that eventually leads to turnover. Six dimensions of job-satisfaction, which represent distinct features of the jobs of psychiatric nursing personnel, were significant predictors of the intention to leave. Satisfaction with professional growth and workload were particularly influential. In the first case, nursing personnel are clearly more prone to intend to quit if they feel frustrated with the lack of advancement and growth opportunities available to them in psychiatric settings. The effects of autonomy, relationships with coworkers, and workload on intention to quit may reflect frustration with constraints on nursing personnel's ability to treat long-term psychiatric patients according to accepted nursing and treatment protocols. Carrying heavy case loads while lacking sufficient autonomy to carry out procedures and the support of other staff may prove daunting for nursing personnel and may frustrate their ability to devote the intensive, personal attention to individual patients required for 
successful psychosocial treatment or rehabilitation.

Although our path model confirmed that turnover follows an attitude-decisional-behavior sequence, satisfaction with coworker relations and job hazards deviated from this pattern and affected turnover more directly. This may mean that if nursing personnel perceive that they are subject to physical hazards in the routine performance of their duties or feel that they are not in a supportive environment with respect to their coworkers, they may leave the position without any prior intention to do so. Some patients in psychiatric settings are prone to unpredictable and sometimes dangerous behavior (Peter \& Ryan, 1994). If subjected to repeated physical threats or physical stress in the routine performance of their duties, nursing personnel may consider leaving those jobs for a better situation. However, an injury due to lifting patients or from a violent assault by a patient may also lead to immediate exit from the position.

Satisfaction with coworkers is also important because effective care in psychiatric settings depends on cooperative, team-based interaction among providers (Vinokur-Kaplan, 1995; Zautra, Eblen, \& Reynolds, 1986). This means nursing personnel are highly dependent on their coworkers. If nursing personnel recognize over time that they cannot count on or expect support from their coworkers they will very likely begin planning to leave. A dramatic incident indicating lack of support from coworkers might also be sufficient to cause nursing personnel to leave the unit without prior planning (Packard \& Motowidlo, 1987).

Based on our results we believe that satisfaction with workload may affect intention to quit and turnover through its relationship with satisfaction with job hazards. Higher workload may promote greater job hazards, either through increased physical demands that accompany more work or because insufficient staffing does not permit the time to engage in therapeutic prevention designed to reduce to the probability of physical assaults from patients (Prescott, 1986).

Our path model also supports the hypothesis that different individuals and groups may be predisposed to hold particular attitudes toward work and their jobs. For example, in the study settings LPNs and aides had more direct contact with patients than RNs, which exposed them to greater potential physical hazards in their work. Such hazards, therefore, represent a more significant factor in their desire to leave the unit.

LPNs and aides also are more likely to suffer from constrained autonomy in contrast with other members of the provider team (Grieshaber, Parker, \& Deering, 1995; Landeweerd \& Boumans, 1988; Parkes \& Rabenau, 1993). Traditionally, these nursing personnel have operated under the direct supervision of the RNs, physicians, and other professional providers. Their jobs have also been characterized by routine performance of tasks and roles that rarely call for individual judgment and decision making (Church, 1987). Thus, LPNs and aides may experience great dissatisfaction with their level of autonomy because they deal with patients regularly but are not able to make treatment decisions independently (Grieshaber et al., 1995). Although LPNs and aides have been included as multidisciplinary treatment team members in many psychiatric settings recently, their relatively low status may continue to reinforce strong feelings of dissatisfaction in how they and others define their roles on the team.

We found that RNs, relative to LPNs and aides, tended to be more dissatisfied with workload. This attitude may arise because RNs often supervise other providers and must make nursing decisions for all of their patients. Their role can become a bottleneck for carrying out patient care on the unit. LPNs and aides were more comfortable with the number of patients they cared for, but RNs may have felt overwhelmed due to their wider span of control. Analogous concerns have been expressed by RNs in acute care settings during downsizing (Irvine \& Evans, 1995). In addition, workload may be more salient to RNs in long-term psychiatric settings because of the emphasis on rehabilitation in these settings. This activity requires considerable time and continual interaction with patients, and RNs may feel that they lack the time to perform these duties to their satisfaction.

We measured years of education attained separately from occupation or level of training. Surprisingly, although RNs usually attain higher levels of education than LPNs or aides, the effects of education level on job-satisfaction differed from those of nurse training. Increased educational attainment was related to greater satisfaction with workload, although RNs were less satisfied than LPNs and aides with workload. At the same time, increased educational attainment was related to dissatisfaction with work hazards, whereas RNs were more satisfied than LPNs and aides with work hazards.

Unlike the other background characteristics, age exhibited a single, direct path to turnover. The effect of age may simply reflect the general labor pattern of greater stability among older members 
of the workforce. Older workers may reflect the end point of a selection process in which only those whose needs fit well with the position remain on the job. In addition, as workers age, they may be less attractive to new employers and have greater human capital investment in their current place of employment. The opposite is true for younger workers, making them more mobile and, thus, more likely to leave.

Our finding on the role of gender in the process of turnover is consistent with previous findings in the literature. In their meta-analysis of organizational commitment Mathieu and Zajac (1990) showed that women tend to have higher levels of organizational commitment then men. Riordan and Shore (1997) have recently corroborated this finding. Thus, it is not surprising in our study to find that men were more likely to express a greater intent to leave the job than women.

Although these findings lend insight into the process of turnover, we also found that our model is better at accounting for variation in intention to quit and job-satisfaction than actual turnover. This may be a function of the sample we used. Nursing personnel in the VA operate within a closed system where unrestricted movement in and out of organizational settings is more constrained than in private organizations. It should be noted, however, that such constraints also make the test of our model less sensitive to variation in institutional or system characteristics, a common weakness of many turnover studies.

Our results indicated that the causes of nursing turnover in long-term psychiatric units were multifaceted and complex. Specific elements of jobsatisfaction may affect turnover either directly or through intention to quit. Importantly, our findings also indicated that the causes and process of turnover vary across different groups of nursing personnel. For example, LPNs and aides were disproportionately affected by job hazards and lack of autonomy relative to RNs, whereas RNs were more likely to be sensitive to workload issues.

Our findings indicate that strategies for reducing nursing turnover and increasing job-satisfaction in psychiatric settings may fall short if they are not sensitive to diversity among different types of nursing personnel (Cameron et al., 1994; GrayToft \& Anderson, 1985). For example, efforts to reduce assaultive behavior and physical stress may represent the cornerstones of retention strategies aimed at LPNs and aides. The same approach however may not be as effective for reducing turnover among RNs. Similarly, because workload concerns appear to weigh more heavily on
RNs' decision to quit, augmenting staff or reducing patient load might be core features of strategies to prevent exiting among RNs.

Despite the differences between psychiatric and nonpsychiatric nursing and between work issues salient to RNs in contrast to LPNs and aides, several themes are common to previous work on nursing job-satisfaction and turnover. In particular, the emphasis on promotional and professional opportunities as a factor in the decision to leave the job appears to be a universal concern of nursing personnel in a variety of settings. The absence of channels for upward mobility in health care organizations forces many nurses into lateral moves to advance their careers or in some cases compels them to leave the profession altogether. Until health care organizations introduce mechanisms such as educational advancement programs that allow nursing personnel to acquire additional degrees and attain professional recognition and promotion within the organization, problems of jobsatisfaction and voluntary turnover are likely to persist.

\section{REFERENCES}

Anthony, W.A. (1990). Psychiatric rehabilitation: The need to integrate with treatment services. Focus on Mental Health Services Research, 4(2), 1-2.

Anthony, W.A., Cohen, M., Farkas, M., \& Cohen, B.F. (1988). Clinical care update: The chronically mentally ill. Case management-more than a response to a dysfunctional system. Community Mental Health Journal, 24, 219-228.

Asher, H.B. (1983). Causal modeling (2nd ed.). Beverly Hills: Sage Publications.

Benedict, M.B., Glasser, J.H., \& Lee, E.S. (1989). Assessing hospital nursing staff retention and turnover: A life table approach. Evaluation \& The Health Professions, 12(1), 73-96.

Blegen, M.A., \& Mueller, C.W. (1987). Nurses' job-satisfaction: A longitudinal analysis. Research in Nursing \& Health, 10, 227-237.

Cameron, S.J., Horsburgh, M.E., \& Armstrong-Stassen, M. (1994). Job satisfaction, propensity to leave and burnout in RNs and RNAs: A multivariate perspective. Canadian Journal of Nursing Administration, 7(3), 43-64.

Caudill, M., \& Patrick, M. (1989). Nursing assistant turnover in nursing homes and need satisfaction. Journal of Gerontological Nursing, 15(6), 24-30.

Church, O.M. (1987). From custody to community in psychiatric nursing. Nursing Research, 36, 48-55.

Cnaan, R.A., Blankertz, L., Messinger, K.W., \& Gardner, J.R. (1988). Psychosocial rehabilitation: Toward a definition. Psychosocial Rehabilitation Journal, 11(4), 61-77. 
Cotton, J.L., \& Tuttle, J.M. (1986). Employee turnover: A meta-analysis and review with implications for research. Academy of Management Review, 11, 55-70.

Coward, R.T., Hogan, T.L., Duncan, R.P., Horne, C.H., Hilker, M.A., \& Felsen, L.M. (1995). Job satisfaction of nurses employed in rural and urban long-term care facilities. Research in Nursing \& Health, 18, 271-284.

Cudeck, R., \& Browne, M.W. (1983). Cross-validation of covariance structures. Multivariate Behavioral Research, 18, 147-157.

Davis-Blake, A., \& Pfeffer, J. (1989). Just a mirage: The search for dispositional effects in organizational research. Academy of Management Review, 14, $385-400$.

Davis-Sacks, M.L. (1991). Final Report: Evaluation of Collaborative Program in Psychiatry (Final report No. BAT0502A). Ann Arbor, MI: VA Great Lakes Region HSR\&D Program.

Depp, F.C., Arnold, E., Dawkins, J., \& Selzer, N. (1983). Predicting tenure decisions of psychiatric nursing assistants: Individual and work related factors. Research in Nursing \& Health, 6, 53-59.

Dunkin, J., Stratton, T., Harris, T.R., Juhl, N., \& Geller, J. (1994). A Predictive Model for Retention of Rural Nurses. Unpublished manuscript, Grand Forks, The University of North Dakota Rural Health Research Center.

Goodell-Tarnowski, T., \& Van Ess Coeling, H. (1994). Outcomes of nurses' job satisfaction. Journal of Nursing Administration, 24(11), 36-41.

Gray-Toft, P.A., \& Anderson, J.G. (1985). Organizational stress in the hospital: Development of a model for diagnosis and prediction. Health Services Research, 19, 753-774.

Grieshaber, L.D., Parker, P., \& Deering, J. (1995). Job satisfaction of nursing assistants in long-term care. Health Care Supervisor, 13(4), 18-28.

Hackman, J.R. (1987). The design of work teams. J.W. Lorsch (Ed.), Handbook of Organizational Behavior (pp. 315-342). Englewood Cliffs, N.J.: PrenticeHall.

Hinshaw, A.S., \& Atwood, J.R. (1983). Nursing staff turnover, stress, and satisfaction: Models, measures, and management. Annual Review of Nursing Research, 1, 133-153.

Huey, F., \& Hartley, S. (1988). What keeps nurses in nursing: 35,00 nurses tell their stories. American Journal of Nursing, 88, 181-188.

Irvine, D.M., \& Evans, M.G. (1995). Job satisfaction and turnover among nurses: Integrating research findings across studies. Nursing Research, 44, 246-253.

Jöreskog, K.G., \& Sörbom, D. (1993). LISREL 8 user's reference guide. Chicago, IL: SSI Scientific Software International.

Klem, L. (1995). Path Analysis. In L.G. Grimm \& P.R. Warnold (Eds.), Reading and understanding multivariate statistics (pp. 65-97). Washington, DC: American Psychological Association.

Landeweerd, J.A., \& Boumans, N.P.G. (1988). Nurses' work satisfaction and feelings of health and stress in three psychiatric departments. International Journal of Nursing Studies, 25, 225-234.

Lichtenstein, R. (1984). Measuring the job satisfaction of physicians in organizational settings. Medical Care, 22, 56-68.

Lucas, M.D., Atwood, J.R., \& Hagaman, R. (1993). Replication and validation of anticipated turnover model for urban registered nurses. Nursing Research, 42, 29-35.

Mathieu, J.E., \& Zajac, D.M. (1990). A review and meta-analysis of the antecedents, correlates and consequences of organizational commitment. Psychological Bulletin, 102, 171-194.

Minkoff, K. (1987). Resistance of mental health professionals to working with the chronic mentally ill. New Directions for Mental Health Services, 33(Spring), 3-20.

Mobley, W.H., Horner, S.O., \& Hollingsworth, A.T. (1978). An evaluation of precursors of hospital employee turnover. Journal of Applied Psychology, 63(4), 408-410.

Mueller, C.W., \& Price, J.L. (1990). Economic, psychological, and sociological determinants of voluntary turnover. Journal of Behavioral Economics, 19, 321-335.

Packard, J.S., \& Motowidlo, S.J. (1987). Subjective stress, job satisfaction, and job performance of hospital nurses. Research in Nursing \& Health, 10, 253-261.

Parasuraman, S. (1989). Nursing turnover: An integrated model. Research in Nursing \& Health, 12, 267-277.

Parkes, K.R., \& Rabenau, C.V. (1993). Work characteristics and well-being among psychiatric health-care staff. Journal of Community \& Applied Social Psychology, 3, 243-259.

Peter, E.C., \& Ryan, J. (1994). A multiregional study of nurses' beliefs and attitudes about work safety and patient assault. Hospital and Community Psychiatry, 45, 1104-1108.

Prescott, P.A. (1986). Vacancy, stability, and turnover of registered nurses in hospitals. Research in Nursing \& Health, 9, 51-60.

Price, J.L., \& Mueller, C.W. (1981). Professional turnover: The case of nurses. New York: SP Medical and Scientific Books.

Riordan, C.M., \& Shore, L.M. (1997). Demographic diversity and employee attitudes: An empirical examination of relational demography within work units. Journal of Applied Psychology 82, 342-358.

Salancik, G.R., \& Pfeffer, J. (1978). A social information processing approach to job attitudes and task design. Administrative Science Quarterly, 23, 101-130.

Schneider, B. (1987). The people make the place. Personnel Psychology, 40, 437-453.

Stamps, P.L., \& Piedmonte, E.B. (1986). Nurses and work satisfaction: An index for measurement. Ann Arbor, Michigan: Health Administration Press Perspectives.

Staw, B.M., \& Ross, J. (1985). Stability in the midst of 
change: A dispositional approach to job attitudes. Journal of Applied Psychology, 70, 469-480.

Vinokur-Kaplan, D. (1995). Enhancing the effectiveness of interdisciplinary mental health treatment teams. Administration and Policy in Mental Health, 22, 521-530.

Weisman, C.S., Alexander, C.S., \& Chase, G.A. (1980). Job satisfaction among hospital nurses: A longitudinal study. Health Services Research, 15, 341-364.
Weiss, H., \& Adler, S. (1984). Personality and organizational behavior. In B. Staw \& L. Cummings (Eds.), Research on organizational behavior (pp. 1-50). Greenwich, CT: JAI Press.

Zautra, A.J., Eblen, C., \& Reynolds, K.D. (1986). Job stress and task interest: Two factors in work life quality. American Journal of Community Psychology, 14, 377-393. 